\title{
400 meters freestyle pacing strategy and race pace training in age-group swimmers
}

\author{
JED M. TIJANI ${ }^{1 *}$, PATRYCJA LIPIŃSKA ${ }^{2}$, ABDERRAOUf BEN ABDERRAHMAN $^{1}$ \\ ${ }^{1}$ Higher Institute of Sports and Physical Education of Ksar Said, University of Manouba, Tunisia. \\ ${ }^{2}$ Institute of Physical Education, Kazimierz Wielki University, Bydgoszcz, Poland.
}

\begin{abstract}
Purpose: This study aimed to characterize the $400 \mathrm{~m}$ freestyle pacing strategy, the effect of post-race feedback, and individualised race-pace training. Methods: Twenty male swimmers (13.4 \pm 1.0 years) were randomly assigned into two groups. The experimental group used training monitoring based on intensities around $400 \mathrm{~m}$ pace ( 92 and $97 \%$ of $400 \mathrm{~m}$ speed), while, for the control group different heart rate zones (EN2 and EN2+) were used as an intensity criterion. The training volume was the same for both groups. A maximal $400 \mathrm{~m}$ freestyle simulated competition was performed before and after the 3 weeks period to determine intensities and to assess changes in performance. The rate of perceived exertion and heart rate values were also evaluated. Results: A fast start in the first 50-100 m, then a constant speed in the middle of the race and an end-spurt during the last 50-100 m was the pacing pattern adopted by the majority of the swimmers. Significant main effects of time were observed for $400 \mathrm{~m}$ time ( $p=0.001$; ES 3.39; very large). Results revealed significant pre-to-post improvements from $328 \pm 26.3 \mathrm{~s}$ to $317 \pm 19.4 \mathrm{~s}$ in the experimental group and from $329 \pm 25.2 \mathrm{~s}$ to $321 \pm 21.1 \mathrm{~s}$ in the control group. Conclusions: All the swimmers adopted almost the same parabolic pacing strategy before and after the training program with some differences in seconds that have made the strategy of the experimental group better balanced during the post-training test. Both training methods induced significant improvements in $400 \mathrm{~m}$ performance, to a greater extent for the training using intensities near $400 \mathrm{~m}$ race pace.
\end{abstract}

Key words: swimming, training monitoring, training zones, young competitive, pacing

\section{Introduction}

To achieve optimal performance, it is essential for athletes to use their available energetic resources efficiently. To avoid wasting kinetic energy, all possible energy stores should have been used before finishing a race, but not so far from the end of the race that a meaningful slowdown can occur [7]. An optimal pacing strategy to distribute effort over the course of the race is considered a key element in the final outcome [21], [25]. Swimming is biomechanically inefficient with high drag force, therefore, appropriate swimming pace is crucial to avoid any undesirable onset of sudden fatigue, which will determine loss of stroke power, coordination and speed [14], [26].
Swimming pace can be defined as the speed at which a swimmer completes a distance, and is an important variable to be monitored to obtain a better performance [22], [26]. Pacing profiles in swimming vary by event distance as well as by stroke [15]. In short-duration sporting events lasting less than $30 \mathrm{~s}$ (e.g., $50 \mathrm{~m}$ swimming) an all-out pacing strategy is typically employed [1]. The $100 \mathrm{~m}$ event is also classed as a sprint event and there is some evidence characterising pacing profiles in these events [15], in which swimmers typically adopted a positive pacing strategy [13], [21]. In middle-distance events including 200 and $400 \mathrm{~m}$ distances, the most commonly used pacing strategies across a range of competitive levels are parabolic; a fast start that may be accounted for by the dive and $15 \mathrm{~m}$ underwater stroke followed by an evenly paced

\footnotetext{
* Corresponding author: Jed M. Tijani, Higher Institute of Sports and Physical Education of Ksar Said, University of Manouba, Tunisia. Phone: +21622444794, e-mail: jed.tijani@yahoo.com

Received: August 28th, 2021

Accepted for publication: October 19th, 2021
} 
mid-section and a fast end spurt [14], [17], or fast-start even; a fast start followed by a relatively even pace [14], [21]. Similar to middle-distance freestyle events, parabolic pacing is typically utilised in freestyle events of $800 \mathrm{~m}$ or above, where swimming velocity is greatest at the start and end of the race [11]. Other studies in both middle and long-distance events shows the need to conserve energy at the start, swim at a consistent pace in the middle sections and then increase velocity in the latter stages [17], [21]. While pacing is important in all swimming events, it is suggested to be most noticeable in events of $400 \mathrm{~m}$ or longer [13] when the ability to swim at an even pace in the mid-sections followed by an end spurt in the final lap(s) is critical for a successful outcome [15]. More recently, Lipinska and Hopkins [12] in their study on $400 \mathrm{~m}$ pacing in elite female swimmers concluded that the proportions of swimmers who could improve performance due to changes in pacing were smaller than in their $1500 \mathrm{~m}$ study, probably because pacing must become less important as the duration of the event decreases and the intensity approaches maximal effort throughout the race.

There is no widespread acceptance of any pacing method for swimming [2]. Traditionally, coaches manage the swimming pace by giving visible coded signals to swimmers with their hands, while standing on the poolside. Some studies have reported that the modalities of feedback given to the swimmer could affect swimming pace [18], [28]. It is speculated that the regulation of exercise pace is dictated by a combination of the ability to resist fatigue, feedback integration, anticipatory forecasting and previous experience [27]. The optimal pacing strategy can be a learned pattern, based on extensive experience gained during training and previous competitions [8], [9]. Additionally, Skorski et al. [23] indicated that simulated competition (SC) can be used for investigating manipulations of pacing pattern during training and it can be speculated that patterns stored in the long-term memory during training can be carried into real competition (RC).

It was indicated in a recent review of Menting et al. [16] that, because of the scarcity in literature on youth swimmers' pacing behaviour, it is difficult to provide a detailed description of their pacing behaviour. No direct differences in the pacing profiles of youth and adult swimmers were found. However, pacing profiles of youth swimmers were evidently more variable, and these swimmers demonstrated difficulties in self-selecting of the most beneficial pacing profile. This could indicate that youth swimmers struggle to regulate their energy distribution in the most efficient manner [16]. Young swimmers' incompetence in stabilising their pacing behaviour may be related to the finding that pacing skills are contingent on prior experience and the level of (meta-) cognitive functioning, which require time to fully develop [6], [8]. A recently proposed model for developing athletes' pacing skills emphasises the importance of both the experiential and self-regulatory aspects of skill learning [6]. To the best of the authors' knowledge, no previous research investigated the importance of feedback and training on the pacing strategy in swimming. Thus, the aim of our study was to characterize the pacing strategy during $400 \mathrm{~m}$ freestyle SC, the effects of post-race feedback and individualised race pace training in age-group competitive swimmers. Our hypothesis suggests that age-group swimmers may generally adopt a pacing strategy similar to that of elite swimmers and that some individual differences may be seen among them according to their experience and/or their self-regulation methods, and that, after a specific race-pace training period, the chosen strategy will be better balanced.

\section{Materials and methods}

\section{Participants}

Twenty male 13-14-year old swimmers took part in our study. All participants were competitive swimmers of the same national team, had previous experience in swimming training of at least 6 years and trained approximately 5 to 6 days a week during the previous year, with a total distance of 24 to $26 \mathrm{~km}$ a week. Their performance level in the $400 \mathrm{~m}$ freestyle event is $67.2 \pm 4.9 \%$ of the world record. A medical examination was carried out before the start of the study. None of the participants reported recent injuries that could interfere with study participation. The subjects and their parents were informed of the benefits and risks of the investigation prior to signing parental written informed consent. All participants were asked not to participate in other physical activities and to maintain their usual diet and sleeping habits for the duration of the study. Each measure was treated in accordance with standard ethical guidelines of the Ethics Committee of the hosting institution, which approved the experimental protocol $(\mathrm{N}-16-2018)$ in the spirit of the Helsinki Declaration.

\section{Measurements}

The testing sessions were undertaken before training (pre-training) and after 3 weeks of the training program (post-training). The pre-training session was performed $48 \mathrm{~h}$ prior to the start of the training pro- 
gram. The post-training session began $48 \mathrm{~h}$ after training cessation. All tests were conducted in the afternoon at $05: 00 \mathrm{pm}$ in a 50 meters indoor pool (air temperature $26 \pm 1{ }^{\circ} \mathrm{C}$, water temperature $27 \pm 1^{\circ} \mathrm{C}$ ). All anthropometric measurements were performed in the morning by the same examiner. Body mass was measured accurate to $0.1 \mathrm{~kg}$, with the subject in light clothing and without shoes, using an electronic scale (Tanita HD 317). Height was determined accurate $0.5 \mathrm{~cm}$ with a measuring tape fixed to the wall.

Participants performed the exercise test after a standardized warm-up of $1000 \mathrm{~m}$, directed by the head coach of the team. The exercise test consisted of a 400 meters freestyle SC for determination of the pacing strategy. As described by Skorski et al. [23], lap times were measured during the turn when swimmers touched the wall with their feet and final times when they touched the wall with their hand. Times were recorded using two manual stopwatches (DT2000 - Digi Sport Instruments; France). The same experienced investigators measured times for the same swimmers during each test.

Immediately upon the event completion, heart rate (HR) was measured with the HR monitor (Polar S610 HR Monitor, Polar Electro Oy, Kempele, Finland) while the swimmer was always in the water next to the wall. Before the event, all the swimmers were instructed to press the receiver on their chest upon their arrival (in the $5 \mathrm{~s}$ interval) and keep it pressed until the examiner who launched the polar watch instruct them to remove the receiver. A rating of perceived exertion (RPE) was assessed using the Borg 6-20 RPE scale [3] at the end of the event, immediately after measuring the HR.

\section{Design and procedures}

During our study, the participants were randomly assigned into two groups: An experimental group (EG; $n=10$; age $13.4 \pm 1.1$ years; height $152.5 \pm 8.9 \mathrm{~cm}$; body mass $47.4 \pm 7.9 \mathrm{~kg}$ and BMI $20.4 \pm 8.4$ ) that followed a training program according to intensities calculated from their $400 \mathrm{~m}$ mean speed in relation with the critical velocity $(\mathrm{CV})$ and a control group $(\mathrm{CG} ; n=10$; age $13.5 \pm 1.0$ years; height $153.2 \pm 7.4 \mathrm{~cm}$; body mass $48.1 \pm 7.5 \mathrm{~kg}$ and BMI $20.5 \pm 7.4)$ that continued its regular training program according to HR measurement and training zones.

After the test, specific speed and time calculations were made. The experimental group (EG) attended a feed-back meeting in which swimmers were informed with the pacing strategies used by elite swimmers during international competitions. They were also informed in detail about their personal results and pacing strategies including their own results (lap and $100 \mathrm{~m}$ times) and the times corresponding to intensities in relation with their personal $400 \mathrm{~m}$ race pace. These intensities were then used during the main sets of the training sessions. The coach and his assistant followed the times and rest intervals and ensured that all the swimmers complied with the need of the set. The training program is presented in Table 1.

The EG completed 8 to 9 sessions per week during the training period ( 25 sessions and 105 kilometres, in total), with 3 sessions per week, in which the objective was to swim interval training main sets at intensities near to $400 \mathrm{~m}$ race pace ( 92 to $97 \%$ of the mean T400 speed). The $92 \%$ corresponds to the $\mathrm{CV}$ as found by Zacca et al. [30], while $97 \%$ corresponds to $105 \%$ of the CV. Exercise to rest ratio of $1: 6$ and $1: 4$ was applied for the intensity of 92 and $97 \%$, respectively. The control group (CG) participated in the same testing protocol and swimmers were only informed about their final T400 swimming times without receiving any information about their lap times and pacing strategies. The CG also completed 8 to 9 sessions per week during the training period ( 25 sessions and

Table 1. Weekly training organization for both experimental and control groups

\begin{tabular}{|c|c|c|c|c|c|c|c|}
\hline & \multicolumn{3}{|c|}{ Experimental group } & \multicolumn{3}{|c|}{ Control group } & \multirow{2}{*}{$\begin{array}{c}\text { EG and CG } \\
\text { Examples } \\
\text { of main sets }\end{array}$} \\
\hline & $\begin{array}{c}\text { No. of } \\
\text { sessions }\end{array}$ & $\begin{array}{l}\text { Distance } \\
{[\mathrm{km}]}\end{array}$ & $\begin{array}{c}\text { Intensities and } \\
\text { distances of } 3 \text { sessions } \\
\text { during each week }\end{array}$ & $\begin{array}{c}\text { No. of } \\
\text { sessions }\end{array}$ & $\begin{array}{l}\text { Distance } \\
{[\mathrm{km}]}\end{array}$ & $\begin{array}{c}\text { Intensities and } \\
\text { distances of } 3 \text { sessions } \\
\text { during each week }\end{array}$ & \\
\hline Week 1 & 8 & 33 & \multirow{3}{*}{$\begin{array}{l}\text { 1) } 92 \% \text { of } v 400: \\
100 \mathrm{~m}-400 \mathrm{~m} \text { sets }\end{array}$} & 8 & 33 & \multirow{2}{*}{$\begin{array}{l}\text { 1) (EN2) HR 150-170 : } \\
100 \mathrm{~m}-400 \mathrm{~m} \text { sets }\end{array}$} & \multirow{2}{*}{$\begin{array}{l}\text { 1) } 10 \times 200 \mathrm{~m} \mathrm{R} 25^{\prime \prime} \\
\text { or } 7 \times 300 \mathrm{~m} \mathrm{R} 35^{\prime \prime}\end{array}$} \\
\hline Week 2 & 8 & 35 & & 8 & 35 & & \\
\hline Week 3 & 9 & 37 & & 9 & 37 & $\begin{array}{l}\text { 2) (EN2+) HR 160-180 : } \\
50 \mathrm{~m}-200 \mathrm{~m} \text { sets }\end{array}$ & $\begin{array}{l}\text { 2) } 20 \times 100 \mathrm{~m} \mathrm{R} 20^{\prime \prime} \\
\text { or } 12 \times 150 \mathrm{~m} \mathrm{R} 25^{\prime \prime} \\
\end{array}$ \\
\hline $\begin{array}{l}\text { Exercise } \\
\text { to rest } \\
\text { ratio }\end{array}$ & \multicolumn{3}{|c|}{$\begin{array}{l}\sim 1: 6 \text { and } 1: 4 \text { for the } v 400 \text { intensity of } 92 \% \text {, } \\
\text { and } 97 \% \text {, respectively. }\end{array}$} & \multicolumn{3}{|c|}{ 1:6 and 1:4 for the EN2 and EN2+ respectively } & \\
\hline
\end{tabular}

$\mathrm{v} 400$ - mean velocity during $400 \mathrm{~m}$ test; EN2 - endurance zone 2; EN2+- endurance zone 2+; R - rest time between repetitions. 
105 kilometres in total) based on HR intensity and training zones described by Urbanchek [29]. HR verification and recordings were completed by an assistant coach during the rest periods, each swimmer was measured thrice, one time in each one-third of the main set.

\section{Statistical analyses}

Data were expressed as mean and standard deviation (mean \pm SD). Statistical analyses were performed by Statistical Package for Social Sciences (v.20. SPSS, Chicago, USA). Normality of distribution was assessed with the Shapiro-Wilk's test; the equality of variance was verified with the Levene's test. A mixed-model ANOVA was performed to analyse the differences in swimming patterns over different time points (laps) during the race (within factor), between EG and CG (between factor), for both pre-and post-training T400. Differences within and between groups were calculated using a two-way analysis of variance (ANOVA) for repeated measures. If group $x$ time interactions turned out to be significant, a Newman-Keul's post hoc test was conducted. Additionally, effect sizes (ES) were determined from ANOVA output by converting partial eta-squared to Cohen's d. Moreover, withingroup ES were computed using the following equation: $\mathrm{ES}=($ mean post - mean pre $) /$ pooled SD. ES were considered trivial $(<0.2)$, small $(0.2-0.59)$, moderate (0.6-1.19), large (1.2-1.99), very large $(2.0-4.0)[10]$. The level of significance was set at $5 \%$ $(p<0.05)$. In addition, the comparison was also made in the values (in seconds) to illustrate the difference in lap and $100 \mathrm{~m}$ times between the races more clearly.

\section{Results}

T400, HR, and RPE values measured before (pretraining) and after (post-training) the training program in both EG and CG are presented in Table 2.
No significant differences between groups in baseline (pre-training) were detected for any of the analysed parameters $(p>0.05)$. The main effect of time was found for T400 ( $p=0.001$; ES 3.39; very large). There was no group $x$ time interaction for any of the analysed parameters $(p>0.05)$. Relatively important differences in the values (in seconds) in T400 were detected for both EG and CG.

Lap and $100 \mathrm{~m}$ times and the difference between laps and between $100 \mathrm{~m}$ times are presented in Table 3. Delta $(\Delta)$ corresponds to the difference between two laps (e.g., $\Delta$ lap 1-2) or between two $100 \mathrm{~m}$ (e.g., $\left.\Delta 1^{\text {st }}-2^{\text {nd }} 100 \mathrm{~m}\right)$.

No statistical differences between EG and CG lap times (lap1 to lap 8) and in $100 \mathrm{~m}$ times (first to fourth $100 \mathrm{~m})$ in pre-and post-training were found $(p>0.05)$. The only important differences were detected in the values (in seconds). For both EG and CG, a comparison between lap times during pre-training testing revealed a statistical difference between lap 1 and all the other laps $(p<0.05)$, the same finding was observed for lap 2 and 8 . On the other hand, lap 4 was similar to lap 3 to $7(p>0.05)$. For EG, a comparison between lap times during post-training testing revealed a statistical difference between lap 1 and all the other laps $(p<0.05)$, the same finding was observed for lap 2 and 8. However, lap 5 was similar to lap 3 to 7 ( $p>$ 0.05 ). For $\mathrm{CG}$, a comparison between lap times during post-training testing revealed a statistical difference between lap 1 and all the other laps $(p<0.05)$, the same finding was observed for lap 8. On the other hand, lap 5 was similar to lap 4 to 7 and lap 2 was similar to lap $8(p=0.238)$. In both EG and CG, a comparison between each $100 \mathrm{~m}$ time during pre-training testing revealed a statistical difference between the first $100 \mathrm{~m}$ and all the other ones $(p<0.05)$, the same finding was observed for the fourth $100 \mathrm{~m}$. However, the second $100 \mathrm{~m}$ was similar to the third one $(p=0.848)$. Comparison between each $100 \mathrm{~m}$ time during posttraining testing revealed a statistical difference be-

Table 2. T400, HR, and RPE values measured before (pre-training) and after (post-training) the training program in both EG and CG

\begin{tabular}{|c|c|c|c|c|c|c|c|c|c|}
\hline & \multicolumn{3}{|c|}{ Experimental group } & \multicolumn{3}{|c|}{ Control group } & \multicolumn{3}{|c|}{$p$-value (effect size) } \\
\hline & $\begin{array}{c}\text { Pre- } \\
\text {-training }\end{array}$ & $\begin{array}{c}\text { Post- } \\
\text { training }\end{array}$ & Evolution & $\begin{array}{c}\text { Pre- } \\
\text {-training }\end{array}$ & $\begin{array}{c}\text { Post- } \\
\text {-training }\end{array}$ & Evolution & $\begin{array}{l}\text { Main effect } \\
\text { time }\end{array}$ & $\begin{array}{l}\text { Main effect } \\
\text { group }\end{array}$ & $\begin{array}{l}\text { Interaction } \\
\text { group } x \text { time }\end{array}$ \\
\hline $\begin{array}{c}\mathrm{T} 400 \\
\text { (s) }\end{array}$ & $\begin{array}{l}328.46 \\
(26.25)\end{array}$ & $\begin{array}{l}317.41 \\
(19.39)\end{array}$ & $-3.48 \%$ & $\begin{array}{l}329.07 \\
(25.24)\end{array}$ & $\begin{array}{l}321.04 \\
(21.05)\end{array}$ & $-2.50 \%$ & $\begin{array}{c}p^{p}=0.001^{*} \\
(3.39)\end{array}$ & $\begin{array}{c}p=0.76 \\
(0.21)\end{array}$ & $\begin{array}{c}p=0.396 \\
(0.59)\end{array}$ \\
\hline $\begin{array}{c}\mathrm{HR} \\
(\mathrm{bpm})\end{array}$ & $\begin{array}{l}183.80 \\
(9.06)\end{array}$ & $\begin{array}{l}185.40 \\
(7.89)\end{array}$ & $+0.87 \%$ & $\begin{array}{l}184.20 \\
(6.21)\end{array}$ & $\begin{array}{l}185.00 \\
(4.83)\end{array}$ & $+0.43 \%$ & $\begin{array}{c}p=0.593 \\
(0.36)\end{array}$ & $\begin{array}{c}p=1.000 \\
(0.000)\end{array}$ & $\begin{array}{c}p=0.790 \\
(0.17)\end{array}$ \\
\hline $\begin{array}{c}\text { RPE } \\
\text { (U.A) }\end{array}$ & $\begin{array}{l}17.90 \\
(1.10)\end{array}$ & $\begin{array}{l}18.50 \\
(1.78)\end{array}$ & $+3.35 \%$ & $\begin{array}{l}18.00 \\
(0.66)\end{array}$ & $\begin{array}{l}18.20 \\
(0.78)\end{array}$ & $+1.11 \%$ & $\begin{array}{c}p=0.318 \\
(0.7)\end{array}$ & $\begin{array}{c}p=0.785 \\
(0.19)\end{array}$ & $\begin{array}{c}p=0.522 \\
(0.44)\end{array}$ \\
\hline
\end{tabular}

* - significant difference between pre and post, * $p<0.005$; T400 - time recorded during $400 \mathrm{~m}$ swimming; CV - critical velocity; HR - heart rate; RPE - rating of perceived exertion. 
Table 3. Differences between lap and $100 \mathrm{~m}$ times

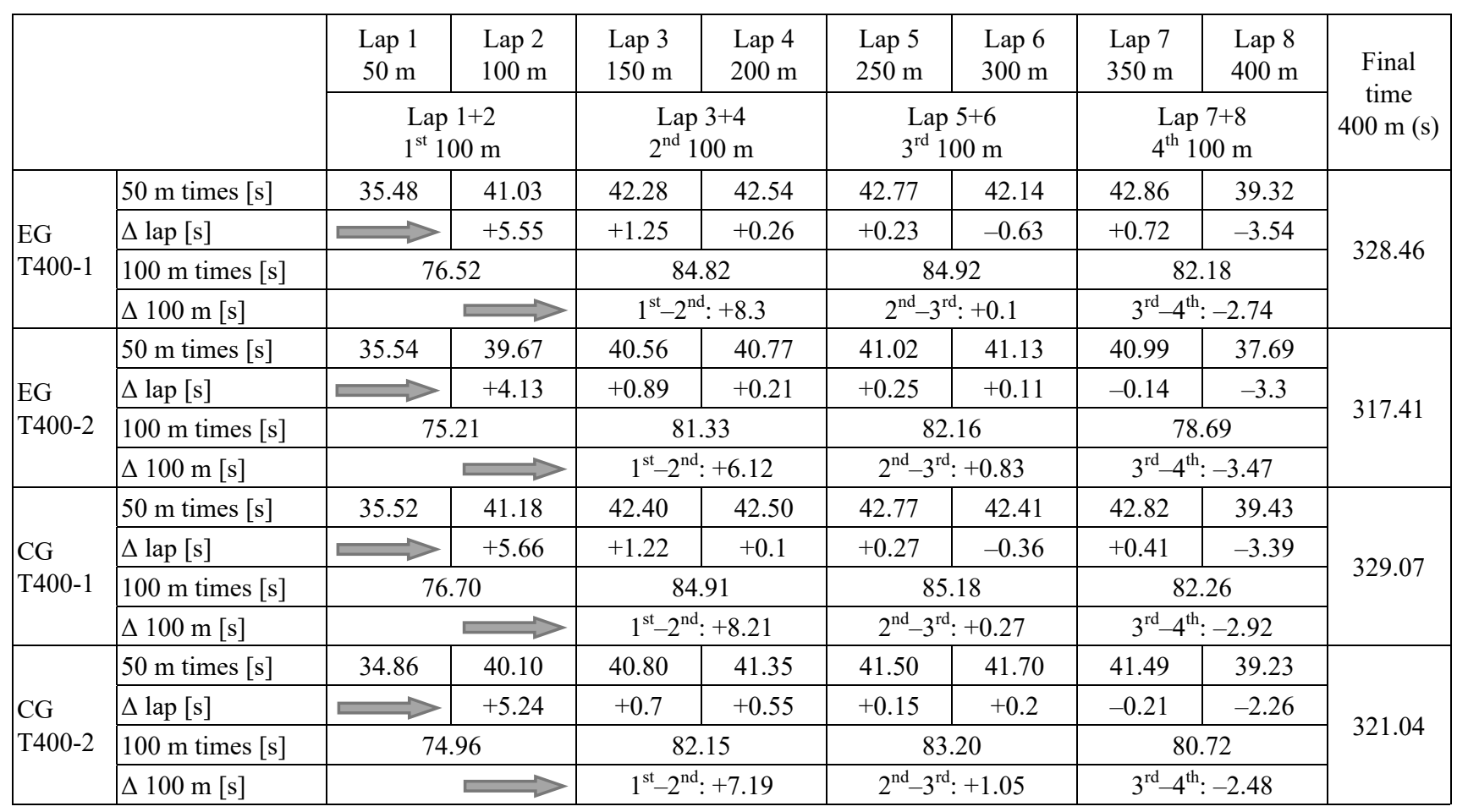

T400-1 - pre-training $400 \mathrm{~m}$ test; T400-2 - post-training $400 \mathrm{~m}$ test; $\Delta$ lap - difference in seconds between two laps; $\Delta 100 \mathrm{~m}$ - difference in seconds between two $100 \mathrm{~m}$.

tween all of them $(p<0.05)$ in EG, but in CG, statistical difference was found between the first $100 \mathrm{~m}$ and all the other ones $(p<0.05)$, the same finding was observed also for the third $100 \mathrm{~m}$.

Table 4. Comparison of lap and $100 \mathrm{~m}$ times from pre to post-training

\begin{tabular}{|l|c|c|}
\hline \multirow{2}{*}{} & Experimental group & Control group \\
\cline { 2 - 3 } & T400-1 vs. T400-2 & T400-1 vs. T400-2 \\
\hline Lap 1 & 0.889 & 0.083 \\
\hline Lap 2 & $0.003^{*}$ & $0.008^{*}$ \\
\hline Lap 3 & $0.001^{*}$ & $0.000^{*}$ \\
\hline Lap 4 & $0.002^{*}$ & $0.009^{*}$ \\
\hline Lap 5 & $0.007^{*}$ & $0.002^{*}$ \\
\hline Lap 6 & $0.019^{*}$ & $0.003^{*}$ \\
\hline Lap 7 & $0.027^{*}$ & $0.014^{*}$ \\
\hline Lap 8 & $0.049^{*}$ & 0.815 \\
\hline $1^{\text {st }} 100 \mathrm{~m}$ & 0.059 & $0.018^{*}$ \\
\hline $2^{\text {nd }} 100 \mathrm{~m}$ & $0.001^{*}$ & $0.000^{*}$ \\
\hline $3^{\text {rd }} 100 \mathrm{~m}$ & $0.008^{*}$ & $0.001^{*}$ \\
\hline $4^{\text {th }} 100 \mathrm{~m}$ & $0.042^{*}$ & 0.225 \\
\hline
\end{tabular}

* Significant difference from pre-to-post training $(p<0.05)$.

Comparisons of each lap time from pre- to posttraining sessions are presented in Table 4. Results showed no statistical difference for lap 1 in EG and for lap 1 and 8 in CG $(p>0.05)$, while laps from 2 to 8 in EG and 2 to 7 in CG has changed $(p<0.05)$. On the other hand, when comparing $100 \mathrm{~m}$ times, statistical differences were found in the second, third and fourth ones in EG and in the first, second and third ones in CG $(p<0.05)$. No changes were observed in the first $100 \mathrm{~m}$ in EG $(p=0.059)$ and in the fourth one in $\mathrm{CG}(p=0.225)$.

\section{Discussion}

According to Skorski et al. [23], no difference in the pacing profile could be observed between $\mathrm{RC}$ and $\mathrm{SC}$. This leads to the assumption that SC can be used for investigating manipulations of pacing pattern during training. Furthermore, it can be speculated that patterns stored in the long-term memory during training can be carried into RC. Thus, the purpose of this study was to analyse the pacing strategy during a 400 $\mathrm{m}$ freestyle SC and the effect of post-race feedback and individualised race pace training in age-group competitive swimmers.

During the two testing sessions, swimmers in both groups showed no difference in RPE and HR values ( $\sim 18$ and $\sim 184$, respectively), indicating that all swam at or near their maximal capacities. During the pretraining test, both groups had the same level of per- 
formance, with $328 \mathrm{~s}$ for EG and $329 \mathrm{~s}$ for CG, which corresponds to a difference of $0.18 \%(0.61 \mathrm{~s})$, while after the 3 weeks period EG swimmers swam by $1.13 \%(3.63 \mathrm{~s})$ faster than those of the CG. This difference ( $3.63 \mathrm{~s}$ ) observed in the 400 time-trial after the training period might play an important role in competition ranking and/or medals standings. Given that both groups followed the same periodization scheme and training content, a more important decline in T400 may be due to the importance of post-competition feedback and the training method based on intensities near the $400 \mathrm{~m}$ race pace. This finding is confirmed by Pyne at al. [19], who stated that the progression in performance times from the competition to the competition is presumably related to the beneficial effects of training (e.g., improvement in fitness and conditioning, swimming skills and technique, tactics and pacing strategies, and psychological skills).

Analyses of the difference between laps and between $100 \mathrm{~m}$ times in our study showed that, during the pre-training test, swimmers of both groups adopted the same pacing strategy: a fast start (a very fast first lap and a fast first $100 \mathrm{~m}$ ), then a constant speed during the second and the third $100 \mathrm{~m}$ and, finally, a relatively fast end-spurt during the fourth $100 \mathrm{~m}$, especially during the final lap. It was also noticed that the acceleration in the final lap is relatively moderate. This parabolic pacing strategy observed in our study corresponds to previous findings indicating that in middle-distance events including 200 and $400 \mathrm{~m}$ and longer distances. The most commonly used pacing strategies across the range of competitive levels are parabolic; a fast start that may be accounted for by the dive and $15 \mathrm{~m}$ underwater stroke followed by an evenly paced mid-section and a fast end spurt [14], [17], [23], or fast-start even; a fast start followed by a relatively even pace [14], [21]. These similarities between swimmers from our study and the international elite ones confirm and complement the findings of Robertson et al. [21], who studied the 16 semifinalists and finalists in 9 international competitions over seven years and found no swimmer level-dependent difference in the overall race management pattern.

When analysing the difference between laps and between $100 \mathrm{~m}$ times (Table 3), we can see that, during the post-training test, all swimmers adopted almost the same parabolic pacing strategy with some differences in the values (in seconds) and a more important acceleration in the final lap in EG than in CG. Observed differences made the strategy of EG better balanced which may be due to the importance of postcompetition feedback and the training method based on intensities near the $400 \mathrm{~m}$ race pace. It confirms that the optimal pacing strategy can be a learned pattern, based on extensive experience gained during training and previous competitions [8], [9].

Some authors described pacing as a process of decision-making [20], [24]. It was proposed that effective cognitive control during performance requires both proactive, goal-driven processes and reactive, stimulus-driven processes [4]. Additionally, other researchers consider that pacing strategy is the combination of feedback integration from physiological receptors, psychological forecasting and previous experience [27]. Swimmers from EG improved the performance of their final lap by $3.49 \mathrm{~s}$ vs. $1.54 \mathrm{~s}$ in comparison with $\mathrm{CG}$ and this finding is similar to those in previous research by Mytton et al. [17], who found that the last lap showed the largest differences in absolute, normalized, and relative speed between the medalists and non-medalists. The success associated with a more pronounced end-spurt suggests that medalists were able to call on reserves of energy not available to non-medalists. According to Burnley and Jones [5], this may have been possible due to a lower physiological disturbance in the medallists at this stage of the race, which, in turn, may be caused by their faster VO2 kinetics, greater critical speed and, possibly, greater aerobic capacity, meaning they could produce a slower rise in the slow component and take longer to attain their VO2max.

Coaches generally instruct their swimmers on the competition day to adopt a specific pacing strategy that is generally not applicable. Therefore, it is more judicious to pre-plan pacing strategies based on research and analysis of high-level competitions and also from prior experience of each swimmer. Pacing strategy can be a learned pattern that should be applied during training sessions by designing main sets on intensities close to those of the specific event. Some limitations of the study may be useful to inform and to conduct in future research. Arm stroke parameters, such as stroke length and stroke rate, could be assessed during testing and training sessions and could provide some extra information.

\section{Conclusions}

During the $400 \mathrm{~m}$ freestyle event, age-group competitive swimmers generally adopt pacing strategies similar to those of the elite. It means a fast start in the first 50-100 m, then a constant speed in the middle of the race and the end-spurt during the last 50-100 m. In addition, designing individualised race pace training 
sets at speeds near to those of the specific event are beneficial for the overall performance and for a better balanced pacing strategy

\section{Acknowledgements}

We would like to thank all participants for attending all required testing and training sessions.

\section{References}

[1] ABbiss C.R., LAURSEN P.B., Describing and understanding pacing strategies during athletic competition, Sports Medicine (Auckland, N.Z.), 2008, 38 (3), 239-252.

[2] Altavilla C., Cejuela R., Caballero-Pérez P., Effect of different feedback modalities on swimming pace: which feedback modality is most effective?, Journal of Human Kinetics, 2018, 65, 187-195.

[3] Borg G., Borg's perceived exertion and pain scales, Champaign: Human Kinetics, 1998.

[4] Brick N.E., Mac Intyre T.E., CAmpbell M.J., Thinking and Action: A Cognitive Perspective on Self-Regulation during Endurance Performance, Frontiers in Physiology, 2016, 7, 159.

[5] BURnLey M., Jones A., Oxygen uptake kinetics as a determinant of sports performance, Eur. J. Sport Sci., 2007, 7, 63-79.

[6] ElferinK-Gemser M.T., Hettinga F.J., Pacing and self-regulation: important skills for talent development in endurance sports, International Journal of Sports Physiology and Performance, 2017, 12 (6), 831-835.

[7] Foster C., De Koning J.J., Hettinga F., Lampen J., La Clair K.L., Dodge C., Bobbert M., Porcari J.P., Pattern of energy expenditure during simulated competition, Medicine and Science in Sports and Exercise, 2003, 35 (5), 826-831.

[8] Foster C., Hendrickson K.J., Peyer K., Reiner B., De Koning J.J., Lucia A., Battista R.A., Hettinga F.J., Porcari J.P., Wright G., Pattern of developing the performance template, British Journal of Sports Medicine, 2009, 43 (10), 765-769.

[9] Foster C., De Koning J.J., Thiel C., Evolutionary pattern of improved 1-mile running performance, International Journal of Sports Physiology and Performance, 2014, 9 (4), 715-719.

[10] Hopkins W.G., Marshall S.W., Batterham A.M., Hanin J., Progressive statistics for studies in sports medicine and exercise science, Medicine and Science in Sports and Exercise, 2009, 41 (1), 3-13.

[11] Lipinska P., Allen S.V., Hopkins W.G., Relationships between pacing parameters and performance of elite male 1500-m swimmers, International Journal of Sports Physiology and Performance, 2016, 11 (2), 159-163.

[12] LiPINSKa P., HoPKIns W.G., Pacing Profiles and Competitive Performance of Elite Female 400-m Freestyle Swimmers, Journal of Strength and Conditioning Research, 2020, 34 (1), 218-224.

[13] Maglischo E.W., Swimming fastest, Leeds: Human Kinetics, 2003.
[14] Mauger A.R., Neuloh J., Castle P.C., Analysis of pacing strategy selection in elite 400-m freestyle swimming, Medicine and Science in Sports and Exercise, 2012, 44 (11), 2205-2212.

[15] McGibbon K.E., Pyne D.B., Shephard M.E., Thompson K.G., Pacing in Swimming: A Systematic Review, Sports Medicine (Auckland, N.Z.), 2018, 48 (7), 1621-1633.

[16] Menting S., Elferink-Gemser M.T., Huijgen B.C., Hettinga F.J., Pacing in lane-based head-to-head competitions: A systematic review on swimming, Journal of Sports Sciences, 2019, 37 (20), 2287-2299.

[17] Mytton G.J., Archer D.T., Turner L., SkORSKi S., Renfree A., Thompson K.G., St Clair Gibson A., Increased variability of lap speeds: differentiating medalists and nonmedalists in middle-distance running and swimming events, International Journal of Sports Physiology and Performance, 2015, 10 (3), 369-373.

[18] Perez P., Llana S., Brizuela G., Encarnación A., Effects of three feedback conditions on aerobic swim speeds, Journal of Sports Science and Medicine, 2009, 8 (1), 30-36.

[19] Pyne D., Trewin C., Hopkins W., Progression and variability of competitive performance of Olympic swimmers, Journal of Sports Sciences, 2004, 22 (7), 613-620.

[20] Renfree A., Martin L., Micklewright D., St Clair Gibson A., Application of decision-making theory to the regulation of muscular work rate during self-paced competitive endurance activity, Sports Medicine (Auckland, N.Z.), 2014, 44 (2), 147-158.

[21] Robertson E., Pyne D., Hopkins W., Anson J., Analysis of lap times in international swimming competitions, Journal of Sports Sciences, 2009, 27 (4), 387-395.

[22] SCRuton A., BAKer J., Roberts J., Basevitch I., MerzBaCh V., GORDON D., Pacing accuracy during an incremental step test in adolescent swimmers, Open Access Journal of Sports Medicine, 2015, 6, 249-257.

[23] SkORSKi S., FAude O., Rausch K., MeYer T., Reproducibility of pacing profiles in competitive swimmers, International Journal of Sports Medicine, 2013, 34 (2), 152-157.

[24] Smits B.L., Pepping G.J., Hettinga F.J., Pacing and decision making in sport and exercise: the roles of perception and action in the regulation of exercise intensity, Sports Medicine (Auckland, N.Z.), 2014, 44 (6), 763-775.

[25] Thompson K.G., MacLaren D.P., Lees A., AtKinson G., The effects of changing pace on metabolism and stroke characteristics during high-speed breaststroke swimming, Journal of Sports Sciences, 2004, 22 (2), 149-157.

[26] Thompson K.G., Pacing - Individual Strategies for Optimal Performance, Human Kinetics, 2014.

[27] TUCKer R., NoAkes T.D., The physiological regulation of pacing strategy during exercise: a critical review, British Journal of Sports Medicine, 2009, 43 (6), e1.

[28] Turner A.P., SMith T., Coleman S.G., Use of an audio-paced incremental swimming test in young national-level swimmers, International Journal of Sports Physiology and Performance, 2008, 3 (1), 68-79.

[29] URBANCHEK J., Middle-distance training for all strokes, [in:] D. Hannula, N. Thornton (Eds.), The swimming coaching bible, Vol. II (pp. 235-250), Human Kinetics, 2012.

[30] Zacca R., Fernandes R.J., Pyne D.B., Castro F.A., Swimming training assessment: the critical velocity and the 400-m test for age-group swimmers, Journal of Strength and Conditioning Research, 2016, 30 (5), 1365-1372. 